\title{
College students' English teaching effectiveness research based on network resources
}

\author{
Yuanqing Huang ${ }^{1, a}$ \\ ${ }^{1}$ Neijiang Normal University, Neijiang city, Sichuan province, China \\ ahuangyq629@126.com
}

Keywords: Network, Network resources, College English, English teaching effectiveness

\begin{abstract}
English classroom teaching is under the network environment on the basis of the traditional English teaching, the use of computer network technology to carry out teaching activities. In this new teaching mode, enrich the teaching means and teaching resources, expand the teaching space and capacity, active classroom learning atmosphere, strong then students' interest in learning.
\end{abstract}

\section{Introduction}

Network technology and English course teaching, informative, fast, the activation of the teaching material content, interactive is strong. And can produce a variety of sensory stimulation. Arouse the enthusiasm of eyes, ears, mouth and hands [1]. In network technology and English curriculum integration, hear its voice, and saw the man, the scene, it realizes the language communication and nonverbal communication supplement each other, students can not only hear the pure language, also can "sense" to strengthen the emotion and attitude to understand, to promote its excellent language is deeply appreciate.

Network as a kind of modern high-tech education teaching media, in the English classroom teaching has become a carrier of teaching information and communication tools. This has a strong function of high-tech teaching media to make English classroom teaching become more active and efficient. However, English teaching is a kind of language teaching and interaction, language teaching is to have the sound, tangible, intentionally, sentient beings, is a communication, network and powerful is not a substitute for teachers in the position and role of English teaching, the purpose of its use is to make the English classroom teaching better [1]. So in English classroom teaching under the network environment is not completely let students autonomous learning in the network, but use network optimize English classroom teaching structure, activation of English classroom teaching activities, make the students learn more independently, vivid, lively and efficient [1]. Due to its across time and space, intuitive, vivid, interactive, a variety of forms in the form of information and other characteristics, can strengthen the emphasis in teaching, to resolve the difficulty, students can learn through the media, teachers can also use the multimedia auxiliary teaching, improve the quality and efficiency of classroom teaching.

\section{Network application feasibility and necessity of college English teaching}

Network technology with other technologies incomparable advantages, as it is known to all, it provides a friendly interface, image intuitive interactive learning environment, can provide a variety of graphic audio-visual and sensory stimulation, can according to the way of hypertext, hyperlink organization and a variety of teaching information management discipline knowledge, on the Internet in this way organization construction of knowledge base, database, has become the world's largest information resource, and thus for the formation and development of students' cognitive structure, promote the students about the meaning of the current knowledge in construction is very good, this will also be new teaching mode provides the ideal teaching environment [2]. Originated in the United States, at the same time, because of the network resources online to one of the main language is English, so the Internet has a lot of English information and resources, it virtually provides a more than the other subjects of English teaching resources and learning environment [2]. We all know, the foreign language teaching should cultivate students in listening, speaking, reading, writing and 
translating skills and teach English national culture background knowledge, and the network provided by electronic mail, BBS, chat rooms, virtual classroom for training the ability provides a good resource, environment and tools.

In addition, we explore the application of Internet in college English teaching main reasons: first, college students of English learning in primary and secondary schools have a certain listening, speaking, reading, writing and translating ability, create conditions for the processing of English information. Second, their autonomy and independent learning ability is strong. Third, the knowledge of computer and network have certain understanding and application ability.

\section{How to realize network and effective integration of college English teaching}

The teaching resources under the network environment are open. Media is the multidirectional communication. Transfer system is a multimedia. Knowledge is across time and space limit. This characteristic determines that under the network environment teaching process is: open. Choose autonomy and personalized learning content. Forms of multimedia content arise in the teaching process, students' learning of loose, uncertainty and difficult to control [3]. Computer and multimedia network classroom environment integration time as constraint variables on classroom instruction, student talent of high and low is the index of learning speed, strong ability of students to complete learning tasks less time. Degree of students' learning is the actual learning time changes along with the time needed for a function, as long as there is enough time, can meet the level. But the reality is that we don't have to grasp the standard for unlimited to extend the time of learning, students can only take other means such as providing personalized help and collaboration between students and tutors to relative to extend the students' learning time. Now in Holiday celebrations this unit as an example shows that the specific teaching process.

The students' learning activities Guiding. The content of the teacher according to the unit chose this theme "festival". Just the students' favorite Christmas is coming. Everybody is busy preparing for Christmas presents. The teacher as the theme, assign students to learn the task ahead of time, to let them through the network to understand how the western countries such as Christmas, and compared with the Chinese how to celebrate the Spring Festival, to know what are the differences between Chinese and western cultures [3]. Then discussed according to the passage and students interested in topics into each task: teachers will the reasonable collocation, the class into several groups.

Teacher's helping in students' personality. Due to the network resources are very abundant, students may be overwhelmed at the beginning, and the teacher can give some targeted site, and guides the student to focus on the information related to solve the problem. Each group under the guidance of group leader to collect information, and the information gathered by finishing editing, understanding and learning at the same time [3]. Students in the process of access to the Internet to collect information may encounter difficulties, can be achieved by hands "electronic" and timely feedback to the teacher. Network system for teachers is to answer students' questions, observational learning, the screen tutorial.

Rich knowledge of the research is problem. Students after download the data, via FTP summary to the leader of the machine, the result to team for the information and data collected after the group discussion, communication, consensus, and form a written materials about the research content and presentation materials [4]. The teacher wants to macroeconomic regulation and controls the content of the whole class discussion, makes sure you want to make each group's report, the content of the show. The class has a home page, according to the different topic link to each group online [4]. The students show in under teachers' guidance to make achievements. Teams are free to choose the display mode: report, interview and so on, through the home page of the class to each group to report the results of organic stuff together. Finally through the questionnaire survey form to help students understand and learn what each group discussion, knowledge collection, realize resources sharing.

Typical evaluation of students' learning activities, complete the meaning construction. Evaluation of student work, can take the teachers and students mutual review method. The teacher should the author affirms the achievements of disadvantages complement. When review, should pay attention to dynamic evaluation of the whole research process, and summative evaluation in 
traditional teaching [4]. At the same time, teachers should also lead student learning outcomes and to others within the group member's role in the process of collaboration for discussion and evaluation. At this point, the student through "human-computer interaction" and "interpersonal communication" formed its own point of view, and building up their own "cognitive structure.

\section{Using the Internet to build the effectiveness of the new type of classroom teaching}

Traditional English teaching is a teacher in the face of dozens of students in teaching, and each student because of seat, personality, ability to learn a variety of factors, such as in the English classroom teaching with education and the chance is not equivalent. English classroom teaching under the network environment, through the hands of a multimedia computer advantages to make up for teachers in English classroom teaching in large unable to give each student the drawback of the timely and detailed tutorial. In the process, students can freely according to his ability to learn and prepare click new words in the text, sound shape with the help of the multimedia computer [5]. Learning ability strong students can click a few times, less and less to read a few times, to reduce the basic knowledge and the basic phonetic learning time. Weak learning ability of students can by repeatedly clicking, listen to read it over and over again, master the basic knowledge of basic voice and, without fear of said before them all wrong, pronounce.

In this unique English teaching environment, students learn more customized and personalized. At the same time, the role of the teacher is no longer impart knowledge and skills, and mainly for guide learners according to their own actual situation to determine the appropriate learning goals, helping learners to find the best way to achieve learning goals, encourage learners to practice, to help learners analysis, solve problems, achieve student tutoring, constructing new classroom teaching pattern to self-study, so as to improve the effectiveness of classroom teaching.

Interactive teaching graphic, lead students cooperation. Illustrated for students learning English to provide a large amount of information, but the teaching material in the graphic are static, its connotation has some hidden inside [5]. If the use of multimedia courseware or other such as: electronic teaching means such as films, videos, slides to present, the static materials then the website will be activated, classroom capacity will increase, become informative, interesting coolers, thus greatly improving the teaching efficiency.

Cultivation of originality of thinking, build independent learning opportunities. An obvious characteristic of multimedia is the interactive teaching process. Students can choose according to their abilities, interests for their own learning content, learning process, independently solve problems, to cultivate their originality of thought. Such as memorization, understand a word or to recite the text, such as performance dialogue can guide students to use the advantages of computer multimedia network for human and machine, the birth and birth, and the way such as interaction. Teachers can accord different class type and content designed some small fun exercises. For example: the new target English in the review unit under the seventh grade, I designed a set of word classification practice [5]. Click on the "animal" and putting them into a corresponding "unit", if it is correct, "professional" stays in the "unit" of the lower part, and immediately hear speakers came in a burst of applause, otherwise, "animals" will automatically fall in place. After a period of practice, greatly enhance the students' practical ability, and the activities of the hand directly affect the growth of the brain, so that the students got the training of thinking, intellectual development, do a wide variety of practice their attention and interest in March, strive to get the ear of applause on each question, while teachers do not need to speak, as long as you walked down the platform to hear, see, the computer will give each student a accurate answer.

Outstanding teaching focus on using the modern network technology, break through the difficulties. The students' attention and interest are the important factors that affect the quality of teaching. For students, learning interest is often their learning motivation directly, and the network technology and reasonable utilization of English curriculum integration can make these factors was optimized [6]. During class, to match with different movements and join a different voice, in such an environment, abstract things and getting specific sentences, image; reduce the students' cognitive 
difficulty. Train the students' observation, and ensure the smooth progress of the learning process, improve the learning efficiency.

To participate in the personalized learning by using modern network technology guides the student. In network technology and English curriculum integration, PowerPoint courseware application methods such as media, new content can be adjusted at any time, the students can actively participate in, make classroom teaching vivid, effective and provide multi-angle, multi-channel graphic and audio and video, and can better support students "do things" in English, can achieve the best teaching effect. Students in class, the teacher are no longer dominating [6].

Network technology and English curriculum integration, teaching about "when the content of the textbook drama has", after the teacher to students to master relevant knowledge for students with a few groups related to the text content, let them use English description. These attempts take the student as the main body autonomy, personalized learning requirements. The whole process is illustrated, affectionately, audio-visual, apply coolers to a drawing the atmosphere, creating dialogue situation, so as to stimulate the students' interest in learning, and prompt them to cultivate communicative competence, and to strengthen the memory.

To improve the effectiveness of classroom feedback by using modern network technology. Multimedia computer can put the TV, VCR, tape recorder, etc of the audio-visual and computer interaction; produce illustrated human-computer interaction forms, vivid image [7]. Which marked characteristics has important significance to the English classroom exercises, it effectively stimulate students' interest in learning, enhance the students' curiosity, but also cultivate the students' ability of observation, become really happy. More important is the new teaching structure reflects the students' main body role fully, human-computer interaction, in this sense is beneficial to exert the principal role of students.

The modern network technology application in English classroom exercises, give students a broad visual space, stimulate the visual nerve of students is sensitive, so that the students attention, careful observation details, provided to comprehension enhancement of teaching materials, help to the teaching of classroom exercises [7]. Teachers in the teaching activities in a timely manner found that students generally existing in the loophole correct in a timely manner. Effective teaching, students learn effectively.

To expand the students' cultural field of vision by using modern network technology. English learning is dependent on the cultural background, to guide students in learning English and learn western social point of view, background of the western languages, etc. Teachers should make efforts to optimize the learning environment, make full use of the outside environment. Using the network technology, the use of our campus network, the network resources, make the teaching break the limit of time and space [7]. Website with lots of English newspapers and periodicals, provide valuable online resources for students, students through this way to understand the culture of other countries, the economic trends, etc.

Actual contact life, promote the "task-based" teaching. "Task-based" teaching emphasize the focus of the teaching process is the completion of the task, not a language form of learning. Language form is in the student's attention on the language sense, the unconscious acquisition, it is "silent even here" in the teaching effect. This task is completed mainly depends on the use of multimedia technology, teaching content contact the actual life. Take the student as the main body use task-based teaching, train the students' ability of creative thinking, encourage students to think for themselves, so they can use learned knowledge to solve new problems [4]. The above tasks set in the Internet environment, closely linked to the real life, not only to cultivate the students' practical ability and the ability to access to data, filter data, and to cultivate the students' consciousness and team spirit of cooperation, give full play to the students imagination and creative ability to use English, the more it is worth mentioning: teachers use multimedia display various around the scene, set up living life material, which is more than the teacher verbal set teaching task of the teaching effect is much better, is fully staffed. 


\section{Summary}

The study of the computer network environment is currently a hot topic in foreign language teaching. In this paper, the effectiveness of computer English teaching under the network environment is studied. Through the computer network environment of the comparison of the autonomous learning and traditional teaching environment, the following conclusions: Effect is more ideal, student's enthusiasm is higher, the independent learning ability, innovation consciousness and cooperative learning ability has improved, especially the basis of good students, they have stronger collecting learning data and information, management, adjust the ability of learning activities, can guarantee efficient learning, they are beneficiaries of the new teaching mode. Poor students in learning English will have more difficulties, they lack of autonomous learning, and the teacher wants to make more guidance and attention to them, enhance their self-confidence.

\section{Acknowledgement}

Sources of Project: Neijiang Normal College Research Project, Project name: College students' English teaching effectiveness research based on network resources, Project number: 15JC14.

\section{References}

[1] H. T. Huang, English curriculum standard, Beijing: people's education press, 2003, pp80-83.

[2] Y.J. Hou, English teaching reform, BBS in northeast China, 2013, vol3, pp.43-47.

[3] X.N. Guo, the necessity of English teaching mode reform, BBS in northeast China, 2015, vol.7, pp.32-35.

[4] M. L. Liu, College English curriculum requirements, Beijing: Higher education press, 2004, pp.8-12.

[5] X.H. Li, Design of college English network courseware based on constructivism theory, Audio-visual education in China, 2004, vol.10, pp.54-58.

[6] D.Y. Zhang, English learning strategies and autonomous learning, Foreign language teaching, 2005, vol.1, pp.12-15.

[7] S.D. Deng, Multimedia foreign language teaching based on the perspective, Foreign language and foreign language teaching, 2013, vol. 9, pp. 25-29. 